\title{
Remaining 0il Distribution Law and Potential Tapping Strategy of Horizontal Well Pattern in Narrow Oil Rim Reservoir with Gas Cap and Edge Water
}

\author{
Xiaolin Zhu, Zongbin Liu, Xinran Wang, Zhiqiang Meng, Qin Zhu \\ Tianjin Branch of CNOOC (China) Limited, Tianjin, China \\ Email: zhuxl4@cnooc.com.cn
}

How to cite this paper: Zhu, X.L., Liu, Z.B., Wang, X.R., Meng, Z.Q. and Zhu, Q. (2019) Remaining Oil Distribution Law and Potential Tapping Strategy of Horizontal Well Pattern in Narrow Oil Rim Reservoir with Gas Cap and Edge Water. World Journal of Engineering and Technology, 7, 355-364. https://doi.org/10.4236/wjet.2019.73026

Received: May 30, 2019

Accepted: July 28, 2019

Published: July 31, 2019

Copyright $\odot 2019$ by author(s) and Scientific Research Publishing Inc. This work is licensed under the Creative Commons Attribution International License (CC BY 4.0).

http://creativecommons.org/licenses/by/4.0/

\begin{abstract}
For thin oil rim reservoir with gas cap and edge water, it is helpful to improve the development effect to find out the distribution law of remaining oil in this kind of reservoirs. For this reason, taking the narrow oil rim reservoir with gas cap and edge water of Oilfield A in Bohai Sea as a case, the main controlling factors, including reservoir structure, fault, gas cap energy, edge water energy and well pattern, affecting the distribution of residual oil in this kind of reservoir were analyzed by using the data of core, logging, paleogeomorphology and production. Then, the distribution law of remaining oil was summarized. Generally, the remaining oil distribution is mainly potato-shaped or strip-shaped in plane. Vertically, it depends on the energy of gas cap and edge water. For the reservoir with big gas gap and weak edge water, the remaining oil mainly lies in the bottom of oil column. And for the reservoir with small gas gap and strong edge water, the remaining oil mainly locates at the top of oil column. Aiming at different distribution modes of remaining oil, the corresponding potential tapping strategies of horizontal wells are put forward: in the late stage of development, for the reservoir with big gas gap and weak edge water, the remaining oil concentrates at the bottom of the oil column, and the position of horizontal well should be placed at the lower $1 / 3$ to the lower $1 / 5$ of the oil column; for the reservoir with small gas cap and strong edge water, the remaining oil locates at the top of the oil column, and the position of horizontal well should be put at the upper $1 / 5$ to the upper $1 / 3$ of the oil column height, vertically. Based on the study on remaining oil of Oilfield A, a potential tapping strategy of well pattern thickening and vertical position optimization of horizontal well was proposed. This strategy guided the effi-
\end{abstract}


cient implementation of the comprehensive adjustment plan of the oilfield. Moreover, 18 infill development wells were implemented in Oilfield A, and the average production of the infill wells is 2.1 times that of the surrounding old wells. It is estimated that the ultimate recovery factor of the oilfield will reach $33.9 \%$, which is $2.3 \%$ higher than that before infilling wells. This study can be used for reference in the development of similar reservoirs.

\section{Keywords}

Thin Oil Rim Reservoir with Gas Cap and Edge Water, Horizontal Well Pattern, Remaining Oil, Vertical Position Optimization, Well Pattern Thickening

\section{Introduction}

Tapping the remaining oil is an important means to keep oil and water production stable during the development of reservoir [1]-[6]. However, the thin oil rim reservoir with gas cap and edge water is a special kind of reservoir and rarely seen at home and abroad [7] [8] [9]. For this kind of reservoir, oil is driven simultaneously by gas cap and edge water from two directions, so that the law of oil and gas migration is complex. It is noted that the gas channeling and water cone would make development effect poor in the middle and late stage of development, and the key to improve development effect of this kind of reservoir is tapping the remaining oil. At present, there is a set of mature research methods of tapping remaining oil for conventional water-drive reservoirs [10]-[17], but there are few studies on the distribution law and tapping potential method of remaining oil for narrow oil rim reservoirs with gas cap and edge water, especially for the reservoirs developed by natural energy. Therefore, the narrow oil rim reservoir with gas cap and edge water of Oilfield A in Bohai Sea is taken as an example, the main control factors affecting the distribution of remaining oil are analyzed. Finally, for reservoirs with different times of gas cap and edge water, such as reservoir with big gas cap and weak edge water, reservoir with small gas cap and strong edge water and so on, the distribution modes of remaining oil and corresponding potential tapping strategies are obtained, which provide technical support for tapping the remaining oil in these reservoirs.

\section{Oil Field Overview}

Oilfield A in Bohai Sea is a special type of reservoir with a gas cap rim oil edge water. It is a structurally controlled short-axis anticline gas top edge water reservoir [18] [19], with a steeper dip angle $\left(>10^{\circ}\right)$, multiple sets of fluid systems in the longitudinal direction, divided into multiple fault blocks on the plane. According to these characteristics, it is divided into multiple development units. The gas top index of each development unit varies greatly (0.2 to 2.5), the water body activity is different ( 5 to 80 times), and the oil rim plane span is narrow $(300$ to $700 \mathrm{~m}$ ), the reservoir thickness is 30 to $90 \mathrm{~m}$, the original dissolved 
gas-oil ratio is $72 \mathrm{~m}^{3} / \mathrm{m}^{3}$, and the crude oil viscosity is 1 to $3 \mathrm{mPa} \cdot \mathrm{s}$. Through core physical property analysis and logging interpretation data, the average porosity and permeability of Shahejie formation are $26.9 \%$ and $251.7 \mathrm{mD}$ respectively. The reservoir is typical narrow oil rim sandstone reservoirs with different gas top energy and different side water energy. The gas top index of the weak top water reservoir in the oilfield is 2.0 , and the water body multiple is 5 times; the gas top index of the small gas top edge water reservoir is 0.5 , and the water body multiple is 60 times. The oilfield was put into development in 2009, using horizontal well layered system and parallel fluid interface failure development. By the end of December 2018, the reservoir had a recovery rate of $22.1 \%$, a gas-oil ratio of $700 \mathrm{~m}^{3} / \mathrm{m}^{3}$, and a water cut of $25 \%$.

\section{Main Factors of Remaining Oil Distribution}

\subsection{Fault}

The structure of Oilfield A is a fault semi-anticline complicated by faults, which is developed on the ancient buried hill background. Within the oilfield, the faults are relatively developed, and the faults are subdivided into different blocks. In the initial stage, most horizontal production wells were larger than $200 \mathrm{~m}$ from the fault. Due to the development of natural gas top and side water energy, the oil near the fault could not be displaced, so the remaining oil enrichment area is still near the fault.

\subsection{Well Network}

Under the premise of structural constraints, the degree of well pattern control seriously affects the remaining oil distribution. When the well network control degree is poor, since the pressure drop mainly exists around the production wellbore, the area between the production wells is often low level of use, thus forming a residual oil enrichment area [1] [2] [3]. Due to the narrow oil rim, Oilfield A was developed with a row of horizontal wells. Due to the limited deployment scope of the well pattern, the oil sand body between the wells cannot be effectively controlled by the well pattern, and thus the displacement cannot be performed, thereby forming the remaining oil between the wells.

\subsection{Gas Cap Energy, Edge Water Energy}

After the formation energy is reduced, the gas cap is ventilated along the top of the structure to the production well, and the edge water is located along the bottom of the structure to the production well. Different gas top energy and side water energy cause different positions of the remaining oil. If the gas cap energy is greater than the edge water energy, the oil layer between the edge water and the production well will be used less, and the remaining oil will be enriched. If the edge water energy is greater than the gas cap energy, the remaining oil between the gas cap and the production well will be enriched.

Horizontal well vertical position 
The vertical position of the horizontal well is an effective means to avoid premature gas cones and water cones in gas top edge water reservoir. At the big gas top and weak edge water reservoir, the closer the oil well is to the gas top, the earlier the gas is trapped, and the remaining oil in the lower part of the oil well is enriched. At the same time, for the small gas cap strong edge water reservoir, the closer the oil well is to the edge water, the more the remaining oil at the top of the well is enriched.

\section{Residual Oil Distribution Law and Pattern}

\subsection{Distribution Law}

Through the analysis of numerical simulation of reservoir performance and residual oil distribution in Oilfield A, its residual oil distribution law mainly contains: 1) there are residual oil enrichment areas between production wells and near faults in horizontal direction; 2) Where the gas cap energy is high, the remaining oil mainly enriched between horizontal production wells and edge water, where the gas cap energy is smaller and the edge water energy is larger, the remaining oil mainly exists between the horizontal productions well and the gas cap in vertical direction.

\subsection{Distribution Pattern in Horizontal Direction}

\subsection{1. "Potato-Like" Residual Oil between Wells}

Oil rim is affected by non-uniform displaced of gas cap and bottom water, the fluid interface is "serrated", and that causes the enrichment of residual oil occurs between wells. Influenced by the energy of gas cap and edge water and horizontal well pattern, the final remaining oil distribution pattern is "potato-like". As shown in Figure 1, there is less residual oil near horizontal production wells,

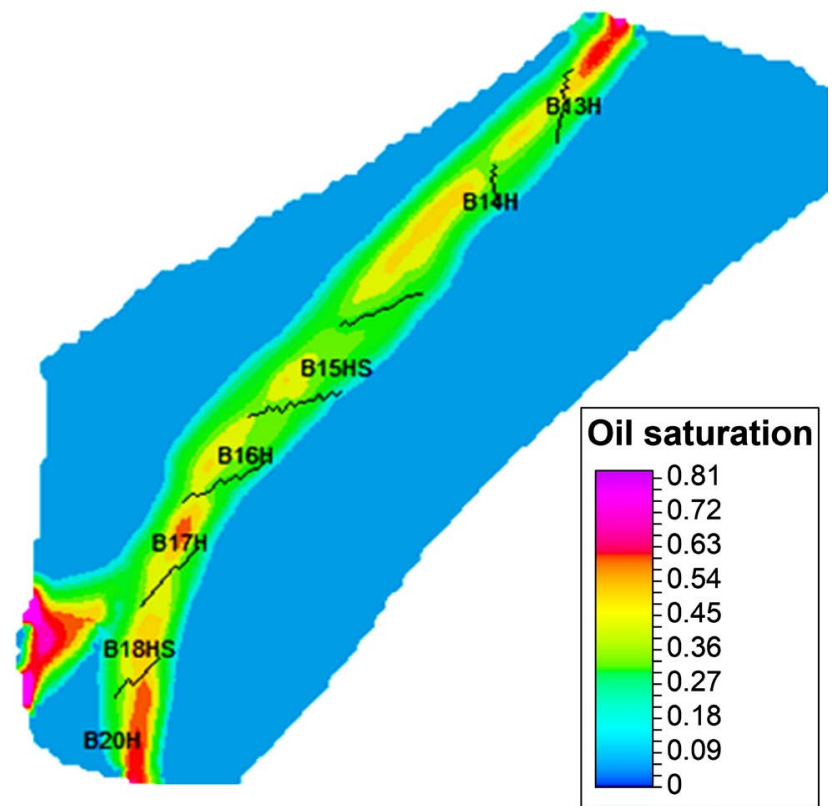

Figure 1. Residual oil distribution map in horizontal direction of Oilfield A. 
remaining oil is enriched between production wells where gas cap and edge water energy cannot effectively displaced the oil, this kind of remaining oil reserves are large, which is an important part of adjusting and tapping potential for the kind of reservoirs.

\subsection{2. "Strip-Like" Residual Oil near Faults}

Reservoirs are divided into different oil, gas and water systems by faults, because of low permeability near faults, that acts the barrier to the seepage underground and the displacement energy inflows unevenly, which leads to a large number of "strip-like" remaining oil near faults (as shown in Figure 1).

\subsection{Distribution Pattern in Vertical Direction}

Macroscopically, the remaining oil in Oilfield A is mainly controlled by gas cap energy and edge water energy. Big gas cap reservoirs have the characteristics of large gas cap index and weak edge water energy, This kind of reservoir mainly relies on gas cap energy supply, and the performance characteristics of production wells are mainly gas channeling, the higher the horizontal location is, the earlier the gas channeling time is and the stronger the gas channeling degree is, resulting in low gas displace efficiency and large-scale enrichment of remaining oil in the middle and lower part of the oil rim. In the early stage of development for reservoirs with strong edge water and small gas cap, horizontal wells are vertically located $1 / 3$ away from the gas-oil interface, because the energy of edge water is larger than that of gas cap, the energy supply of edge water is the main source in the development process, The performance characteristics of production wells are mainly water cones. The oil-water interface rises gradually with the development time, due to the water saturation in the lower part is high and the water saturation in the upper part is low, which leads to the enrichment of remaining oil in the upper part of the production wells.

Meanwhile, each development unit of oilfield is affected by structure, fault and reservoir distribution, which leads to heterogeneity of natural energy distribution in horizontal and vertical direction in the same block. The law of remaining oil enrichment between production wells is also different, and two types of micro-reservoir patterns are proposed.

\subsubsection{Big Gas Cap Reservoirs Contains "Local Small Gas Cap" Pattern}

For the same one reservoir, because of the heterogeneity of natural energy distribution in both horizontal and vertical directions, the law of remaining oil enrichment among oil wells is also different. Although in the same big gas cap condition, the small gas cap appears also existence due to the different fault development. As shown in Figure 1, production well B17H in Oilfield A is characterized by big gas cap, the adjacent production well $\mathrm{B} 18 \mathrm{H}$ is characterized by small gas cap because of fault clamping, its performance characteristic is mainly water cone. For the local development of small gas cap in the background of big gas cap, the remaining oil of this mode still follows the residual oil distribution 
pattern of small gas cap and strong edge water reservoir.

\subsubsection{Small Gas Cap Reservoirs Contains "Local Big Gas Cap" Pattern}

The reservoirs with small gas cap and strong edge water have the characteristics of small gas cap and strong edge water on macro scale, this kind of reservoir is developed by water injection outside the edge, and the design horizontal wells is located at $1 / 3$ of the height of the oil column in the early stage of development. But in the production process, some production wells show the characteristics of big gas top, mainly gas channeling. The remaining oil is mainly concentrated in the lower part of the horizontal wells.

\section{Research on Strategies of Tapping Remaining Oil}

Aiming at the remaining oil distribution law and pattern of gas cap, bottom water and oil rim reservoir, the technology of fine tapping in well pattern is studied. For the distribution patterns of residual oil in "potato-like" and "strip-like" in horizontal direction, residual oil can be tapped by infilling horizontal wells between wells, meanwhile, the vertical location of horizontal wells should be re-optimized according to the distribution pattern of remaining oil in different reservoirs blocks.

According to geological characteristics of gas cap and edge water of Oilfield A, the existing seismic, logging, geological and fluid analysis data are fully utilized, the geological model of gas cap and edge water with dip angle of 12 degrees is established. The length, width and height of the model are $2000 \mathrm{~m}, 450 \mathrm{~m}$ and $280 \mathrm{~m}$, respectively. The horizontal grid step is $20 \mathrm{~m}$ and the vertical grid step is $1 \mathrm{~m}$. A horizontal well is designed for production. The horizontal wells are located in the upper $1 / 5$ to the lower $1 / 5$ of the oil column height respectively. The reservoir model is a normal temperature and pressure system. The relative permeability curve and PVT data are all based on reservoir parameters of Oilfield A. The formation crude oil viscosity is $2 \mathrm{mPa} \cdot \mathrm{s}$. On this basis, the weak edge water reservoirs model with big gas cap (gas cap Index 2.0, water volume multiple 5 times) and strong edge water reservoirs model with big gas cap (gas cap Index 0.5, water volume multiple 60 times) are established with ECLIPSE software, which are simulated the production of horizontal wells in different vertical location respectively (as shown in Figure 2).

For the vertical remaining oil distribution pattern, the numerical simulation of different vertical positions of horizontal wells in narrow oil rim is carried out. By comparing the oil recovery characteristics of horizontal wells at different vertical positions and the production periods without water and gas, the reasonable implementation limits of horizontal wells under different gas cap and edge water energy are given. The results show that for the weak edge water and big gas cap pattern, as shown in Figure 3(a), in early development period, the vertical position of the horizontal well should be located in lower $1 / 3$ of the designed oil column height, in late development period, the remaining oil is concentrated at the bottom of the oil column, and the vertical position of the horizontal well 

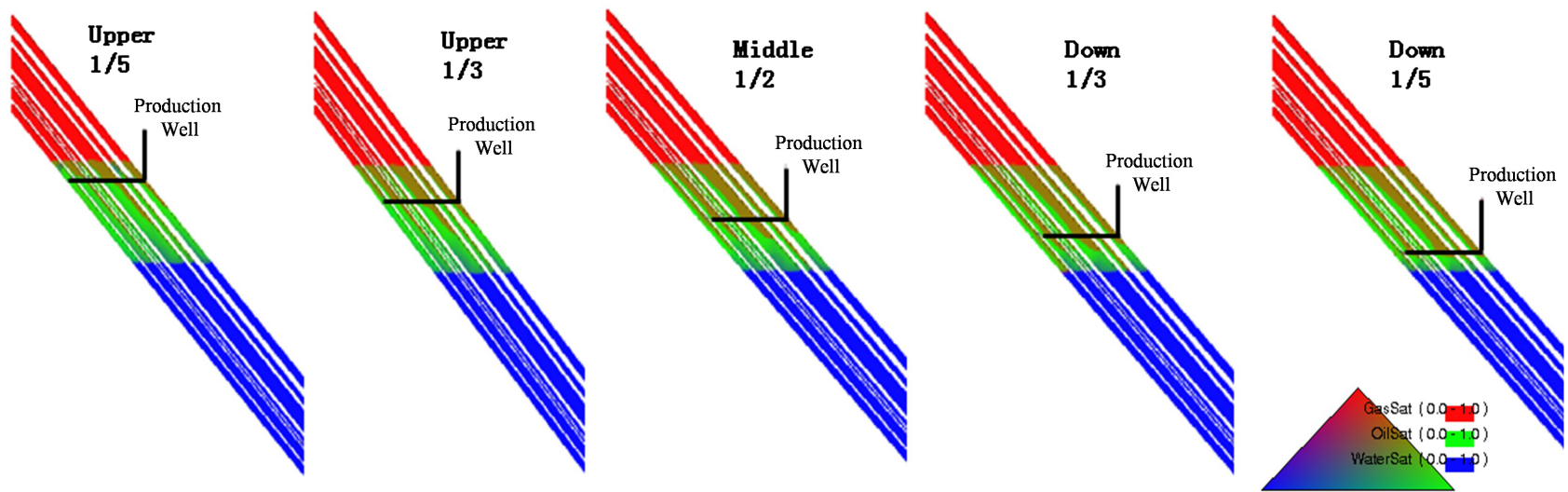

Figure 2. Different vertical positions of horizontal wells (1/5 upper to $1 / 5$ down of oil column height).

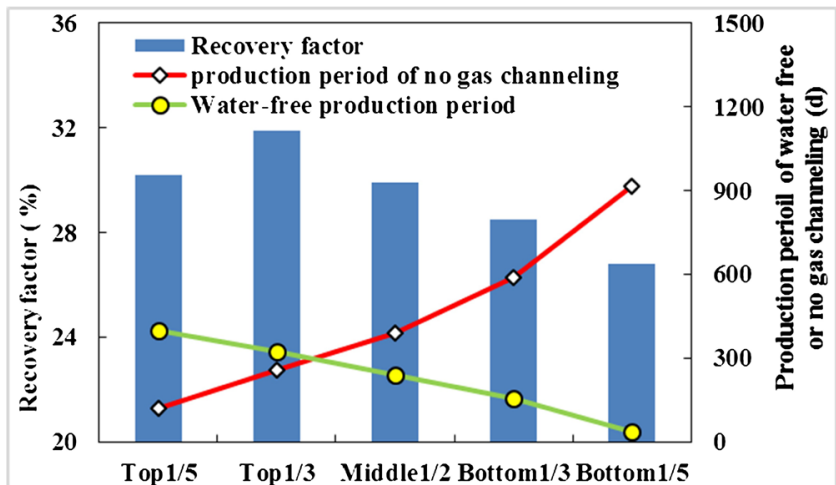

(a)

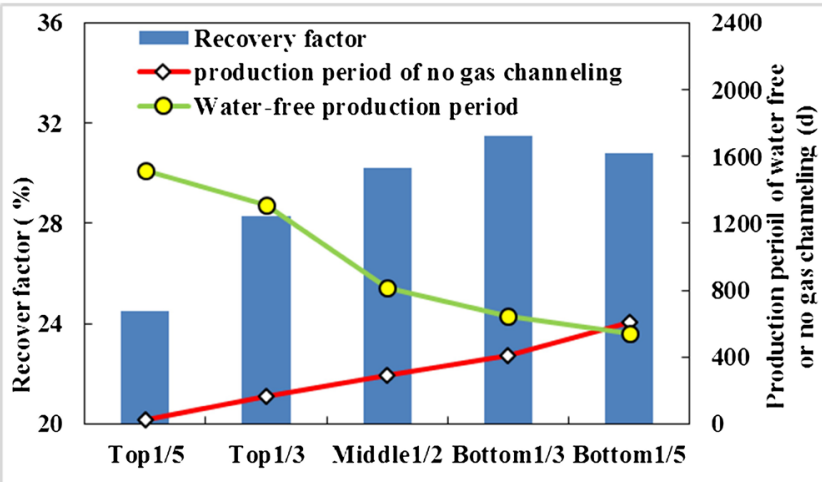

(b)

Figure 3. Numerical simulation results of vertical position optimization in horizontal well of different types of reservoirs. (a) Reservoir with weak edge water and big gas cap pattern; (b) Reservoir with strong edge water and small gas cap pattern.

should be located in lower $1 / 5$ to $1 / 3$ of the oil column height, that is the optimal designed scheme; for the strong edge water and small gas cap pattern, as shown in Figure 3(b), in early development period, the vertical position of the horizontal well should be located in upper $1 / 3$ of the designed oil column height, in late development period, the remaining oil is concentrated at the top of the oil column, and the vertical position of the horizontal well should be located in upper $1 / 5$ to $1 / 3$ of the oil column height, that is the optimal designed scheme.

\section{Application Effect Analysis}

Through the application of the set of technical achievements in this article, distribution of remaining oil in different blocks of the reservoir at present recovery degree is obtained, and 18 infill development wells are projected. At the same time, according to the reservoir physical properties and natural energy of each development well, the vertical position of development wells in different locations is optimized. After putting into production, there are 6 infill wells with daily oil production of more than $100 \mathrm{~m}^{3}$, the average production is 2.1 times that of the nearby old wells, and the gas to oil ratio and water cut are lower than those of the nearby old wells, the development situation were bettered effective- 
ly. The water cut of Oilfield A is controlled within $25 \%$ in 10 years of development stage, the gas to oil ratio is maintained below $700 \mathrm{~m}^{3} / \mathrm{m}^{3}$, and the recovery degree is $22.1 \%$. It is estimated that the recovery rate which is $2.3 \%$ higher than that before infilling adjustment.

\section{Conclusions}

1) According to geological characteristics and development characteristics of narrow oil rim reservoir with gas cap and edge water in Oilfield $\mathrm{A}$, the main controlling factors affecting the distribution of remaining oil in this type of reservoir are analyzed and summarized, they are structure, fault, gas cap energy, edge water energy and well pattern.

2) Under the condition of explicating the main controlling factors of remaining oil in this kind of reservoir, the distribution law of remaining oil is summarized. The remaining oil is "potato-like" and "strip-like" in horizontal direction; in vertical direction, according to the energy of gas cap and edge water, it is concluded that residual oil exists at the bottom of the oil column in the weak edge water reservoir and big gas cap pattern, and at the top of the oil column in the strong edge water reservoir and small gas cap pattern.

3) According to the distribution law of remaining oil in reservoir, the infilling adjustment scheme of horizontal well is proposed: for the weak edge water and big gas cap pattern, the remaining oil is concentrated at the bottom of the oil column, and the vertical position of the horizontal well should be located in lower $1 / 5$ to $1 / 3$ of the oil column height; for the strong edge water and small gas cap pattern, the remaining oil is concentrated at the top of the oil column, and the vertical position of the horizontal well should be located in upper $1 / 5$ to $1 / 3$ of the oil column height.

\section{Acknowledgements}

This project is supported by National Science and Technology Major Project foundation of China in the 13th Five Year Plan. Fund No. 2016ZX05058-001.

\section{Conflicts of Interest}

The authors declare no conflicts of interest regarding the publication of this paper.

\section{References}

[1] Singh, R. and Mohanty, K.K. (2015) Synergy between Nanoparticles and Surfactants in Stabilizing Foams for Oil Recovery. Energy \& Fuels, 29, 467-479. https://doi.org/10.1021/ef5015007

[2] Abramova, A., Abramov, V., Bayazitov, V., et al. (2014) Ultrasonic Technology for Enhanced Oil Recovery. Engineering, 6, 177-184.

https://doi.org/10.4236/eng.2014.64021

[3] Zhu, T., Ogbe, D.O. and Khataniar, S. (2004) Improving the Foam Performance for Mobility Control and Improved Sweep Efficiency in Gas Flooding. Industrial \& En- 
gineering Chemistry Research, 43, 4413-4421. https://doi.org/10.1021/ie034021o

[4] Hahn, P., Ramamohan, T.R. and Slattery, J.C. (1985) Mobility Control in The Displacement of Residual Oil by an Unstable Foam. AICHE Journal, 31, 1029-1035. https://doi.org/10.1002/aic.690310620

[5] Druetta, P., Tesi, P., De Persis, C., et al. (2016) Methods in Oil Recovery Processes and Reservoir Simulation. Advances in Chemical Engineering and Science, 6, 399-435. https://doi.org/10.4236/aces.2016.64039

[6] Li, H.Y., Wang, X.R., Liu, Z.B., et al. (2018) Experimental Study and Field Application of Surfactant-Polymer Flooding in Offshore Oilfield. Journal of Petroleum and Gas Engineering, 9, 32-40. https://doi.org/10.5897/JPGE2018.0285

[7] Berkowitz, B. and Scher, H. (1995) On Characterization of Anomalous-Dispersion in Porous and Fractured Media. Water Resources Research, 31, 1461-1466. https://doi.org/10.1029/95WR00483

[8] Ewing, R. and Lin, Y. (2001) A Mathematical Analysis for Numerical Well Models for NonDarcy Flows. Applied Numerical Mathematics, 39, 17-30. https://doi.org/10.1016/S0168-9274(01)00042-3

[9] Delshad, M. and Pope, G.A. (1989) Comparison of the Three-Phase Oil Relative Permeability Models. Transport in Porous Media, 4, 59-83. https://doi.org/10.1007/BF00134742

[10] Szymkiewicz, A. (2013) Upscaling from Darcy Scale to Field Scale. In: Szymkiewicz, A., Ed., Modelling Water Flow in Unsaturated Porous Media: Accounting for Nonlinear Permeability and Material Heterogeneity, Springer, Berlin, Heidelberg, 139-175. https://doi.org/10.1007/978-3-642-23559-7_5

[11] Chavent, G. and Salzano, G. (1982) A Finite-Element Method for the 1-D Water Flooding Problem with Gravity. Journal of Computational Physics, 45, 307-344. https://doi.org/10.1016/0021-9991(82)90107-3

[12] Setiawan, A., Suekane, T., Deguchi, Y., et al. (2014) Three-Dimensional Imaging of Pore-Scale Water Flooding Phenomena in Water-Wet and Oil-Wet Porous Media. Journal of Flow Control, Measurement \& Visualization, 2, 25-31. https://doi.org/10.4236/jfcmv.2014.22005

[13] Al-Raoush, R.I. and Willson, C.S. (2005) A Pore-Scale Investigation of a Multiphase Porous Medium System. Journal of Contaminant Hydrology, 77, 67-89. https://doi.org/10.1016/j.jconhyd.2004.12.001

[14] Setiawan, A., Nomura, H. and Suekane, T. (2012) Microtomography of Imbibition Phenomena and Trapping Phenomena. Transport in Porous Media, 92, 243-257. https://doi.org/10.1007/s11242-011-9899-2

[15] Blunt, M.J., King, M.J. and Harvey, S. (1992) Simulation and Theory of Two-Phase Flow in Porous Medium. Physical Review A, 46, 7680-7699. https://doi.org/10.1103/PhysRevA.46.7680

[16] Zhu, X.L., Zhu, Z.Q., Wang, L.L., et al. (2016) The Prediction of Water Flooded Thickness in Offshore Thick Reservoir by The Consideration of Gravity Seepage Mechanism. Reservoir Evaluation and Development, 6, 28-31.

[17] Crandall, D., Bromhal, G. and Karpyn, Z. T. (2010) Numerical Simulations Examining the Relationship between Wall-Roughness and Fluid Flow in Fractures. International Journal of Rock Mechanics and Mining Sciences, 47, 784-796. https://doi.org/10.1016/j.ijrmms.2010.03.015

[18] Tong, K.J., Liu, H.Q., Zhang, Y.C., et al. (2015) Three-Dimensional Physical Modeling of Water Flooding in Metamorphic Fractured Reservoirs. Petroleum Explora- 
tion and Development, 42, 538-544. https://doi.org/10.1016/S1876-3804(15)30054-9

[19] Tong, K.J., Li, B., Dai, W.H., et al. (2017). Sparse Well Pattern and High-Efficient Development of Metamorphic Buried Hills Reservoirs in Bohai Sea Area, China. Petroleum Exploration and Development, 44, 590-599.

https://doi.org/10.1016/S1876-3804(17)30071-X 